\title{
ХАРАКТЕРИСТИКА ОЧАГОВ СОVID-19 С РАСПРОСТРАНЕНИЕМ В ОРГАНИЗОВАННЫХ КОЛЛЕКТИВАХ, ЗАРЕГИСТРИРОВАННЫХ В ХАБАРОВСКОМ КРАЕ В ПЕРИОД С АПРЕЛЯ ПО СЕНТЯБРЬ 2020 Г.
}

\author{
${ }^{1}$ Троценко О.Е., ${ }^{2}$ Зайцева Т.А., ${ }^{1}$ Базыкина Е.А., ${ }^{1}$ Корита Т.В., \\ ${ }^{3}$ Гарбуз Ю.А., ${ }^{2}$ Каравянская Т.Н., ${ }^{3}$ Присяжнюк Е.Н. \\ ${ }^{1}$ ФБУН Хабаровский НИИ эпидемиологии и микробиологии Роспотребнадзора, \\ г. Хабаровск; \\ ${ }^{2}$ Управление Роспотребнадзора по Хабаровскому краю, г. Хабаровск»; \\ ${ }^{3}$ ФБУЗ «Центр гигиены и эпидемиологии в Хабаровском крае», г. Хабаровск
}

\section{Резюме}

Цель - выявить эпидемиологические особенности формирования очагов COVID-19 с распространением в организованных коллективах Хабаровского края в период с апреля по сентябрь 2020 г.

Материалы и методы. В период наблюдения зарегистрирован 31 эпидемический очаг с массовым распространением COVID-19 в организованных коллективах Хабаровского края. При проведении эпидемиологического анализа учитывался вклад групповой заболеваемости в общую заболеваемость COVID-19, индекс очаговости (среднее число заболевших в очаге), показатели первичной и вторичной (среди контактных лиц) заболеваемости в организованных коллективах в расчете на 1000 лиц, общавшихся в очаге, удельный вес клинических форм инфекции COVID-19, в том числе в зависимости от типа эпидемического очага. Статистическая обработка данных проводилась с использованием методов непараметрического анализа в программе STATISTICA 6.0. На основе установленных критериев активности эпидемического процесса (ЭП) осуществлялась оценка эпидемической значимости различных типов очагов групповой заболеваемости. Для присвоения ранговых номеров критериев применены методики Хи-квадрата Пирсона, Хи квадрата Пирсона с поправкой Йейтса, в отношении средней длительности существования очага использован метод Манна-Уитни.

Результаты и обсуждение. Самая высокая степень активности ЭП наблюдалась при формировании очагов групповой заболеваемости COVID-19 в социальных стационарных учреждениях, которая проявилась наибольшим (средним на 1 очаг) числом заболевших/инфицированных COVID-19, самыми высокими показателями общей и вторичной (то есть среди контактных в очагах) заболеваемости инфекцией и наибольшей длительностью активности ЭП в очагах. К критериям несколько меньшей, но достаточно существенной активности ЭП в очагах, сформированных в медицинских организациях, следует отнести высокий уровень общей заболеваемости COVID-19, приходящийся в среднем на 1 эпидемический очаг, регистрацию заболеваемости среди контактных с первично заболевшими лицами, наличие летальных исходов среди заболевших в очагах, а также большой вклад медицинских работников в общую групповую заболеваемость COVID-19, зарегистрированную в лечебно-профилактических учреждениях края. Меньшая степень активности ЭП COVID-19 выявлена в очагах групповой заболеваемости, зарегистрированных на крупных промышленных предприятиях и в образовательных организациях, для которых оказались не характерными случаи заболеваний среди контактных лиц и летальные исходы среди инфицированных в очагах. Статистически значимо наиболее высокий удельный вес острых респираторно-вирусных инфекций в структуре лиц, заболевших COVID-19, оказался свойственным для очагов с распространением в образовательных коллективах.

Заключение. На основе представленных критериев активности ЭП может быть использован дифференцированный подход к проведению мер профилактики в очагах 
групповой заболеваемости COVID-19. В коллективах с высоким риском распространения COVID-19, в которых вероятность возникновения вспышечной заболеваемости особенно велика, наиболее оправдан усиленный комплекс постоянно действующих упреждающих мер профилактики новой коронавирусной инфекции.

Ключевые слова: COVID-19, Хабаровский край, очаги групповой заболеваемости, организованные коллективы, активность эпидемического процесса

UDC: 616.98:578834.1Coronavirus-036.2:001.8(571.620)"2020"

\section{CHARACTERISTICS OF COVID-19 GROUP INCIDENCE SPREAD IN ORGANIZED COMMUNITIES IN THE KHABAROVSK KRAI DURING APRIL-SEPTEMBER OF} YEAR 2020

${ }^{1}$ Trotsenko O.E., ${ }^{2}$ Zaitseva T.A., ${ }^{1}$ Bazykina E.A., ${ }^{1}$ Korita $\quad$ T.V., ${ }^{3}$ Garbuz Yu.A., ${ }^{2}$ Karavyanskaya T.N., ${ }^{3}$ Prisyazhnyuk E.N.

${ }^{1}$ FBUN Khabarovsk research institute of epidemiology and microbiology of the Federal service for surveillance on consumers rights protection and human wellbeing (Rospotrebnadzor), Khabarovsk;

${ }^{2}$ Khabarovsk krai Rospotrebnadzor regional office, Khabarovsk;

${ }^{3} \mathrm{FBUZ}$ “Center of hygiene and epidemiology in the Khabarovsk krai”, Khabarovsk

\section{Abstract:}

Objective - to reveal epidemiological peculiarities of COVID-19 group incidence with spread in organized communities of the Khabarovsk krai during April-September of year 2020.

Materials and methods. During the observation period, total number of 31 epidemic cites with spread of COVID-19 in organized communities of the Khabarovsk region were registered. Epidemic analysis included evaluation of group incidence contribution in overall COVID-19 incidence, mean number of infected people in epidemic cites, indices of primary and secondary (including exposed people) incidence in epidemic cites on the expectation of 1000 exposed people, total percentage of COVID-19 clinical forms as well as their estimation for each type of epidemic cite. Statistical analysis was performed via STATISTICA 6.0. Software utilizing nonparametric techniques. Evaluation of epidemic significance of different types of epidemic cites was performed following the terms of evaluated criteria of epidemic process intensity. Pearson's and Chi-squared test including Yates continuity correction if needed were estimated in order to assign ranks of the evaluated criteria. Mann-Whitney U-test was performed in order to rank mean duration of epidemic cites.

Results and discussion. Highest intensity of the epidemic process was revealed under conditions of COVID-19 clusters formation in social residential institutions that manifested with highest (mean for 1 epidemic cite) number of COVID-19 infected people, highest rates of primary and secondary (including exposed people) incidence in epidemic cites as well as longest mean duration of epidemic process. Indices of epidemic cites that were formed in medical facilities had high epidemic intensity but were lower than in social residential institutions. These criteria included high rates of overall COVID-19 incidence in epidemic cites (calculated for one COVID-19 cluster), registration of incidence among exposed people, fatal outcomes of the disease as well as substantial contribution of medical staff in COVID-19 overall group incidence registered in medical institutions of the region. Least intensity of epidemic process of COVID-19 group incidence was revealed in large industrial facilities and educational organizations where no spread of the disease was registered among exposed people as well as absence of lethal outcomes due to COVID-19. Percentage of acute respiratory infections in the structure of COVID-19 infected people was significantly higher in epidemic cites of educational communities.

Conclusion. Based on presented criteria of COVID-19 epidemic process intensity a differentiated approach towards application of preventive measures in epidemic cites of COVID- 
19 group incidence can be utilized. An intensified complex of constantly applied preventive measures against spread of new coronavirus disease is justified in the communities with high risk of COVID-19 spread where chances of outbreaks are high.

Key words: COVID-19, Khabarovsk krai, epidemic cites of group incidence, organized communities, intensity of epidemic process

\section{Введение}

Оперативное реагирование на внезапный рост инфекционной заболеваемости, а также работа по выявлению и установлению причин и условий возникновения вспышек являются важными направлениями деятельности в области обеспечения санитарноэпидемиологического благополучия населения. $\mathrm{K}$ разряду эпидемических вспышек принято относить и очаги групповых случаев заболеваний в организованных коллективах, связанных с одним источником инфекции, обусловленных едиными путями и факторами передачи возбудителя и не выходящих за пределы коллектива [1].

В настоящее время в научной литературе большое внимание уделяется изучению вспышек новой коронавирусной инфекции [2, 3, 4]. На протяжении эпидемии COVID-19 мероприятия по её предотвращению особенно сосредоточены на сокращении числа кластеризованных групп инфекции [5].

На данный момент доказано, что основными путями передачи SARS-CoV-2 являются воздушно-капельный и контактный $[6,7]$, выделение вируса может начинаться за 48 часов до начала появления симптомов, то есть в инкубационном периоде [8], а индекс контагиозности COVID-19 или количество заражений после контакта с инфицированным человеком может составлять 1,4-2,5 [7, 9], в некоторых популяциях даже 6,47 [7, 10]. Вышеперечисленные характеристики новой коронавирусной инфекции способствуют массовому заражению людей в организованных коллективах при наличии источника инфекции в условиях тесного общения.

По данным литературы, особенно подвержены вспышкам новой коронавирусной инфекции специализированные реабилитационные центры и дома престарелых. Так, имеющиеся научные публикации указывают на возникновение эпидемического очага с распространением COVID-19 у 26,2\% пациентов в специализированном реабилитационном медицинском центре, расположенном в штате Вашингтон США [2]. Другое исследование, посвященное анализу групповых заболеваний COVID-19 в доме престарелых штата Вашингтон США, продемонстрировало наличие у 64\% подопечных положительных результатов ПЦР на PHK SARS-CoV-2 в респираторных мазках [3]. Авторы подобных публикаций показывают, что постоянно проводимые профилактические мероприятия (частая влажная уборка с использованием дезинфицирующих средств, ограничение контактов и т.п.) способны предупредить развитие массового инфицирования вирусом SARS-CoV-2 в закрытых коллективах. Например, эффективные противоэпидемические мероприятия свели к минимуму число заразившихся новой коронавирусной инфекцией подопечных дома престарелых в г. Сиэтл (США) - из 80 человек заболевание подтвердилось только у 6 (7,5\%) лиц [4].

Учитывая значительную актуальность вспышечной (групповой) заболеваемости COVID-19 в организованных коллективах на современном этапе, крайне важной представляется детальная её характеристика в отдельно взятом регионе. Более того, характер вспышечной заболеваемости может отражать эпидемическую ситуацию по новой коронавирусной инфекции в целом по региону.

Цель исследования - выявить эпидемиологические особенности формирования очагов COVID-19 с распространением в организованных коллективах Хабаровского края в период с апреля по сентябрь 2020 г.

\section{Материалы и методы}

Эпидемиологическому анализу подвергнуты результаты обследования очагов групповой заболеваемости, отраженные в соответствующих актах эпидемиологического 
обследования очага; месячные формы федерального государственного статистического наблюдения №1 и №2 "Сведения об инфекционных и паразитарных заболеваниях в Хабаровском крае", оперативная информация Управления Роспотребнадзора по Хабаровскому краю и данные ФБУЗ «Центра гигиены и эпидемиологии в Хабаровском крае» о числе заболевших с положительным результатом на COVID-19 с разбивкой по полу, возрасту, социальному статусу, месту инфицирования, по характеру течения заболевания, по формам тяжести течения инфекции.

Период наблюдения составил с 13 апреля по 04 октября 2020 года. Наблюдением охвачен 31 организованный коллектив, в котором сформировались эпидемические очаги инфекции с массовым распространением COVID-19. Границы очага групповой заболеваемости COVID-19 устанавливались в пределах организованного коллектива с пребыванием в нем источника(ов) инфекции, восприимчивых лиц и наличием условий для реализации механизмов передачи инфекции. После выздоровления либо убытия из коллектива последнего больного (или инфицированного лица) очаг сохранял свое значение в течение максимального инкубационного периода (14 календарных дней).

Во всех очагах групповой заболеваемости, сформированных в организованных коллективах, отрабатывались данные на больных и контактных лиц, проводился комплекс необходимых противоэпидемических мероприятий. Эпидемиологическое обследование очагов включало опрос больных и контактировавших с ними лиц, изучение медицинской документации, санитарное обследование очага, ПЦР-исследование на предмет выявления PHK SARS-CoV-2 в респираторных мазках больных и контактных с ними лиц, эпидемиологическое наблюдение в течение времени существования очага для выявления новых заболевших или инфицированных.

При проведении эпидемиологического анализа учитывали вклад групповой заболеваемости в общую заболеваемость COVID-19, индекс очаговости (среднее число заболевших в очаге), показатели первичной и вторичной (среди контактных лиц) заболеваемости в организованных коллективах в расчете на 1000 лиц, общавшихся в очаге, удельный вес клинических форм инфекции COVID-19, в том числе в зависимости от типа эпидемического очага.

Статистическая обработка данных проводилась с использованием методов непараметрического анализа в программе STATISTICA 6.0. Совокупность количественных показателей описывали при помощи средних арифметических величин (M) и стандартных отклонений (SD), ошибки среднего (M), значений медианы (Me), а также десятого (Р10) и девяностого процентилей (P90), т.е. процента значений, которые находились за пределами значения изучаемого персентиля.

Номинальные данные описывались с указанием абсолютных значений и процентных долей. Сравнение номинальных данных проводилось при помощи критерия $\chi^{2}$ Пирсона по формуле:

$$
\chi^{2}=\sum_{i=1}^{T} \sum_{j=1}^{c} \frac{\left(O_{i j}-E_{i j}\right)^{2}}{E_{i j}} \text {, где i - номер строки (от } 1 \text { до r), j - номер столбца (от } 1 \text { до с) }
$$
$\mathrm{O}_{\mathrm{ij}}$ - фактическое количество наблюдений в ячейке $\mathrm{ij}, \mathrm{E}_{\mathrm{ij}}$ - ожидаемое число наблюдений в ячейке $\mathrm{ij}$.

В случае анализа четырехпольных таблиц при ожидаемом явлении хотя бы в одной ячейке менее 10 - рассчитывался критерий $x^{2}$ с поправкой Йейтса, позволяющей уменьшить вероятность ошибки первого типа, т.е. обнаружения различий там, где их нет по формуле:

$$
\chi^{2}=\sum_{i=1} \sum_{j=1}^{c} \frac{\left(\left|O_{i j}-E_{i j}\right|-0,5\right)^{2}}{E_{i j}},
$$

, где i - номер строки (от 1 до r), j - номер столбца

(от 1 до с) $\mathrm{O}_{\mathrm{ij}}$ - фактическое количество наблюдений в ячейке $\mathrm{ij}, \mathrm{E}_{\mathrm{ij}}$ - ожидаемое число наблюдений в ячейке ij. 
В ходе анализа определялись основные критерии активности эпидемического процесса в очагах групповой заболеваемости в организованных коллективах. На основе установленных критериев с использованием метода рангов [11] проводилась оценка эпидемической значимости различных типов очагов групповой заболеваемости. Обоснованность установления ранговых номеров осуществлялась с применением методики Хи-квадрата Пирсона, Хи квадрата Пирсона с поправкой Йейтса, в отношении средней длительности существования очага применялся метод Манна-Уитни:

$U=n_{1} \cdot n_{2}+\frac{n_{x} \cdot\left(n_{x}+1\right)}{2}-T_{x}$

, где $\mathrm{n}_{1}-$ количество элементов в первой выборке, $\mathrm{n}_{2}-$ количество элементов во второй выборке, $\mathrm{n}_{\mathrm{x}}-$ количество элементов в большей выборке, $\mathrm{T}_{\mathrm{x}}$ - сумма рангов в большей выборке.

Полученные различия признавались значимыми при значении р менее 0,05.

Результаты исследования

Важным эпидемиологическим признаком неблагополучия ситуации по COVID-19 в регионе является возникновение очагов с множественными случаями заболеваний в коллективах. В целом, за период с 13 апреля по 04 октября 2020 года заболеваемость в очагах с распространением в организованных коллективах практически не отразилась на тенденциях в динамике общей заболеваемости COVID-19 населения Хабаровского края, за исключением периода с 33 по 36 неделю, в которые отмечены три крупные вспышки в социальных стационарных учреждениях края с общим числом заболевших/инфицированных 270 человек (рис. 1).

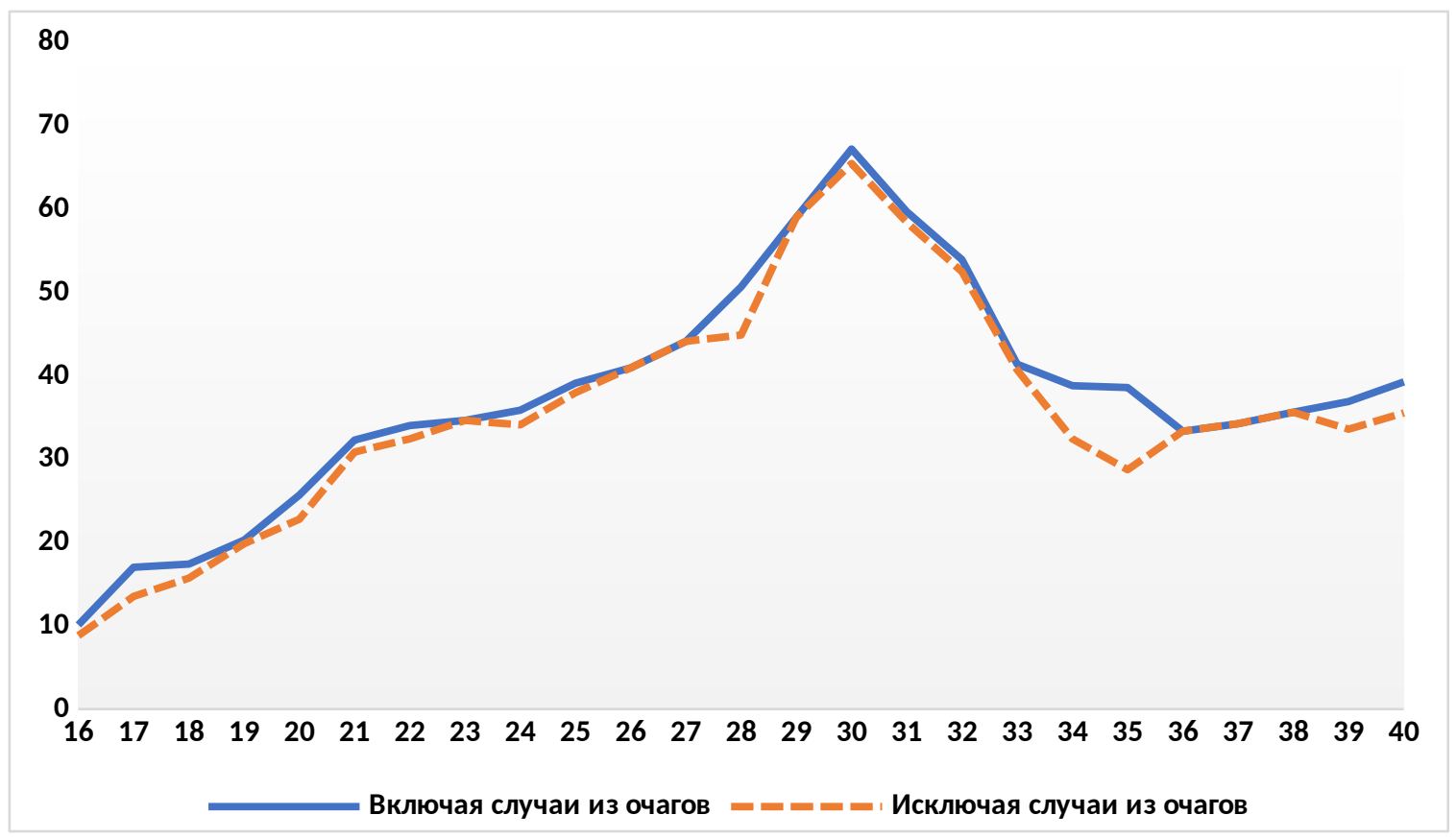

Рис. 1. Сравнительный анализ динамики заболеваемости COVID-19 (на 100 тысяч населения) с учетом и без учета случаев из очагов с распространением в организованных коллективах Хабаровского края.

Примечание: по оси абсцисс указаны календарные недели 2020 г.

Средний удельный вес вспышечной заболеваемости в организованных коллективах составил 5,3 $\pm 0,2 \%$ (658 из 12378 случаев COVID-19), зарегистрированных в крае с 16 по 40 календарную неделю (с 13 апреля по 04 октября 2020 г.). Однако вклад данных эпидемических очагов в показатели недельной заболеваемости населения Хабаровского

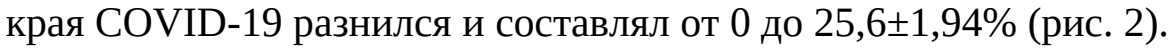


На этапе эпидемии с выраженной (выше +5,0\%) тенденцией прироста заболеваемости COVID-19 (с 16 по 30 неделю или с 13 апреля по 26 июля 2020 г.) наиболее существенный удельный вес групповых случаев заболеваний пришелся на 17 и 18 неделю за счет формирования эпидемических очагов в медицинских организациях (соответственно, 20,5 $22,70 \%$ и 9,6 $1,95 \%$ ), а также на 20 и 28 неделю - за счет вспышечной заболеваемости на предприятиях, использующих вахтовый метод работы


выраженной (меньше -5,0\%) тенденцией к снижению заболеваемости новой коронавирусной инфекцией в Хабаровском крае (с 31 по 36 неделю или с 27 июля по 06 сентября 2020 г.), максимальная доля очаговой заболеваемости была зарегистрирована на

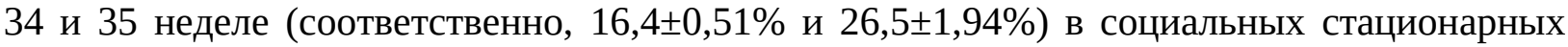
учреждениях (в домах престарелых и инвалидов). На этапе эпидемии с новым подъемом показателей заболеваемости COVID-19 в Хабаровском крае (с 37 по 40 неделю или с 07 сентября по 04 октября 2020 г.) значимый вклад групповой заболеваемости отмечен на 39 и 40 неделе, зафиксированной в образовательных учреждениях (соответственно 9,1ะ1,30\% и $9,5 \pm 1,29 \%)$.

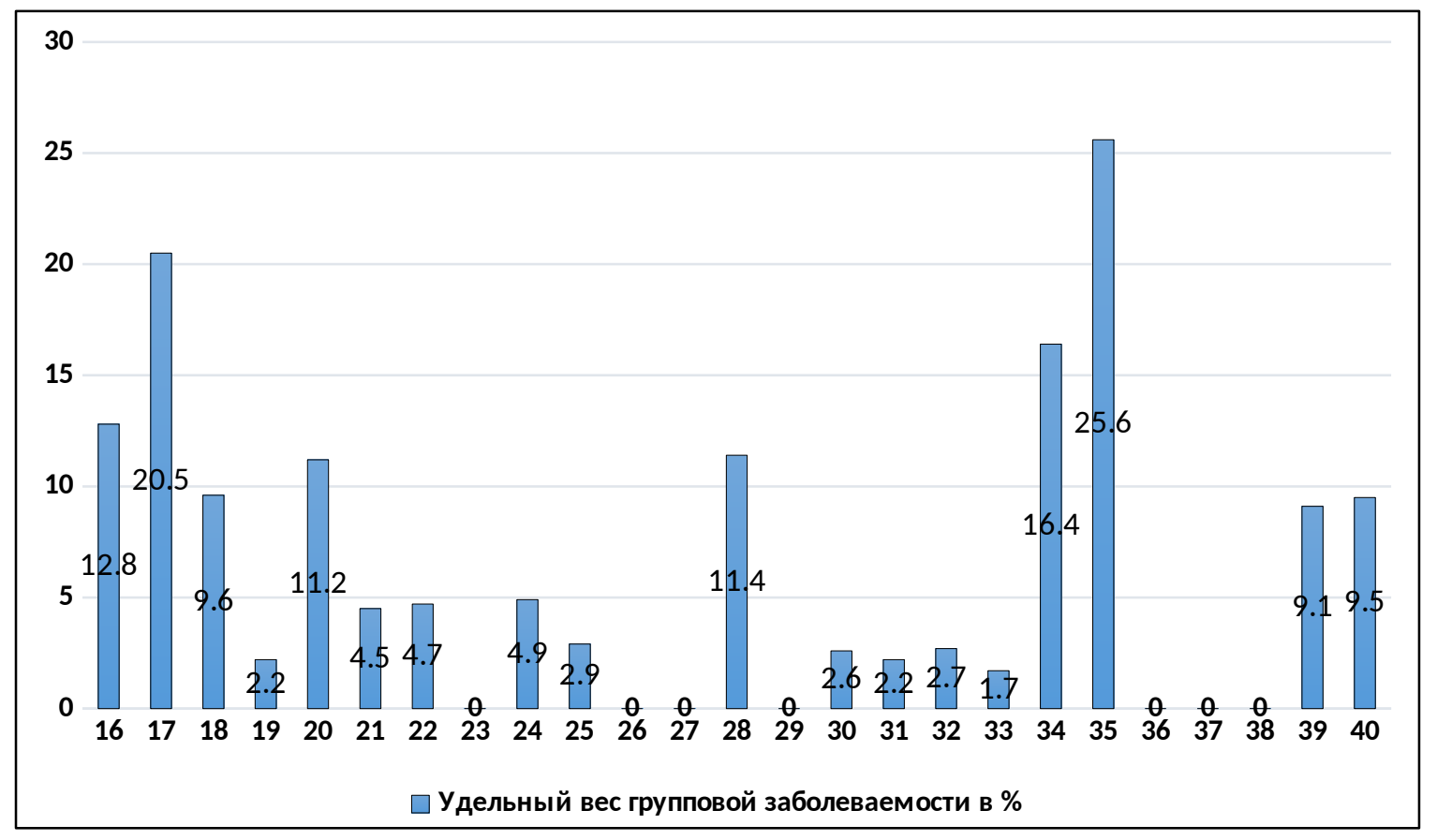

\section{Рис. 2. Удельный вес (в \%) групповой заболеваемости в общей структуре абсолютного числа случаев COVID-19 в неделю (в период с 16 по 40 календарные недели 2020 г.)}

В целом, в Хабаровском крае по состоянию на 04.10.2020 г. кумулятивно зарегистрирован 31 очаг новой коронавирусной инфекции с распространением в организованных коллективах, с общим числом пострадавших 658 человек. Индекс очаговости (ИО), или среднее число инфицированных лиц в 31 очаге, за весь период наблюдения в Хабаровском крае в среднем составил 21,23. Суммарно в 31 очаге оказались 5083 общавшихся человека, в том числе 489 первично инфицированных лиц и 4594 контактных, среди которых впоследствии в пределах 1 инкубационного периода заболели/ инфицировались еще 169 человек. Уровень общей (первичной и вторичной)

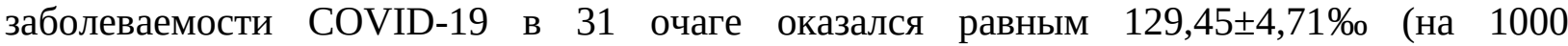
общавшихся в очаге). Соответственно, показатель первичной очаговой заболеваемости, 


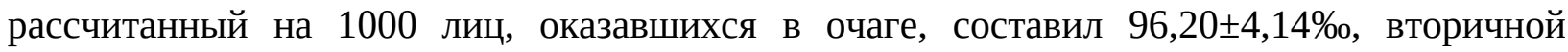
заболеваемости - 33,25 $\pm 2,51 \%$. Среди 658 пострадавших человек заболели внебольничными пневмониями $15,81 \pm 1,42 \%$, больных с признаками ОРВИ оказалось $13,07 \pm 1,31 \%$, лиц с лабораторно подтвержденным бессимптомным течением COVID-19 -

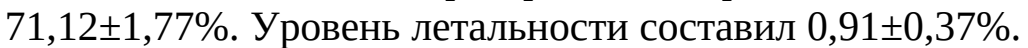

Известно, что показатель продолжительности существования эпидемического очага групповой заболеваемости, определяемый временем пребывания источника и сроком максимального инкубационного периода после контакта с последним заболевшим/инфицированным, может являться отражением своевременности постановки диагноза и проведения необходимых противоэпидемических мероприятий, а также их эффективности [12]. В данном наблюдении, по состоянию на 04.10.2020 г. 14 из 31 очага оставались активными, но на момент написания статьи все изучаемые очаги были сняты с контроля, что сделало возможным проведение анализа длительности активности очагов (табл. 1.).

Таблица 1.

Длительность существования эпидемических очагов COVID-19 с распространением в организованных коллективах Хабаровского края, зарегистрированных в период с 13 апреля по 04 октября 2020 г.

\begin{tabular}{|c|c|c|c|c|}
\hline Очаги & $\begin{array}{c}\text { Дата } \\
\text { регистрации } \\
\text { очага } \\
\end{array}$ & $\begin{array}{c}\text { Дата последнего } \\
\text { случая заражения }\end{array}$ & $\begin{array}{c}\text { Длительность } \\
\text { очага (дата) }\end{array}$ & $\begin{array}{c}\text { Длительность } \\
\text { очага (дни) }\end{array}$ \\
\hline 1 & 13.04 .2020 & 19.04 .2020 & 03.05 .2020 & 21 \\
\hline 2 & 20.04 .2020 & 26.04 .2020 & 10.05 .2020 & 21 \\
\hline 3 & 27.04 .2020 & 03.05 .2020 & 17.05 .2020 & 21 \\
\hline 4 & 27.04 .2020 & 03.05 .2020 & 17.05 .2020 & 21 \\
\hline 5 & 04.05 .2020 & 17.05 .2020 & 31.05 .2020 & 28 \\
\hline 6 & 11.05 .2020 & 17.05 .2020 & 31.05 .2020 & 21 \\
\hline 7 & 11.05 .2020 & 17.05 .2020 & 31.05 .2020 & 21 \\
\hline 8 & 20.05 .2020 & 08.06.2020 & 22.06 .2020 & 34 \\
\hline 9 & 25.05 .2020 & 31.05 .2020 & 14.06 .2020 & 21 \\
\hline 10 & 25.05 .2020 & 31.05 .2020 & 14.06 .2020 & 21 \\
\hline 11 & 08.06 .2020 & 14.06 .2020 & 28.06 .2020 & 21 \\
\hline 12 & 08.06 .2020 & 14.06 .2020 & 28.06 .2020 & 21 \\
\hline 13 & 15.06 .2020 & 21.06 .2020 & 05.07 .2020 & 21 \\
\hline 14 & 06.07 .2020 & 12.07 .2020 & 26.07 .2020 & 21 \\
\hline 15 & 20.07 .2020 & 02.08 .2020 & 16.08 .2020 & 28 \\
\hline 16 & 27.07 .2020 & 02.08 .2020 & 16.08.2020 & 21 \\
\hline 17 & 03.08 .2020 & 16.08 .2020 & 30.08 .2020 & 28 \\
\hline 18 & 17.08 .2020 & 30.08 .2020 & 13.09 .2020 & 28 \\
\hline 19 & 21.09 .2020 & 04.10 .2020 & 18.10 .2020 & 21 \\
\hline 20 & 21.09 .2020 & 04.10 .2020 & 18.10 .2020 & 21 \\
\hline 21 & 21.09 .2020 & 04.10 .2020 & 18.10 .2020 & 21 \\
\hline 22 & 21.09 .2020 & 04.10 .2020 & 18.10 .2020 & 21 \\
\hline 23 & 28.09 .2020 & 04.10 .2020 & 18.10 .2020 & 21 \\
\hline 24 & 28.09 .2020 & 04.10 .2020 & 18.10 .2020 & 21 \\
\hline 25 & 28.09 .2020 & 04.10 .2020 & 18.10 .2020 & 21 \\
\hline 26 & 28.09 .2020 & 04.10 .2020 & 18.10 .2020 & 21 \\
\hline 27 & 28.09 .2020 & 04.10 .2020 & 18.10 .2020 & 21 \\
\hline 28 & 28.09 .2020 & 04.10 .2020 & 18.10 .2020 & 21 \\
\hline 29 & 28.09 .2020 & 04.10 .2020 & 18.10 .2020 & 21 \\
\hline
\end{tabular}




\begin{tabular}{|l|l|l|l|l|}
\hline 30 & 28.09 .2020 & 04.10 .2020 & 18.10 .2020 & 21 \\
\hline 31 & 02.10 .2020 & 02.10 .2020 & 16.10 .2020 & 14 \\
\hline
\end{tabular}

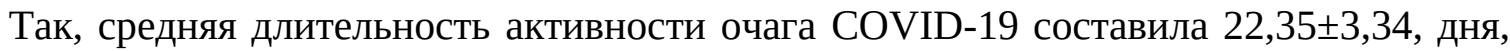
медиана - 21 день (P10=21 день, P90=28 дней), наименьшая длительность активности очага - 14 дней, наибольшая - 28 дней.

В ходе анализа в зависимости от социальной значимости были выделены четыре типа крупных очагов групповой заболеваемости COVID-19, каждый из которых характеризовался разной степенью активности эпидемического процесса: в медицинских организациях (12 очагов), в социальных стационарных учреждениях (3 очага с наибольшим количеством заболевших COVID-19), на промышленных предприятиях (3 очага) и в образовательных учреждениях (13 очагов).

Для медицинских организаций ИО оказался меньше средне-краевого значения и был равен 16,58. Число первично инфицированных лиц в очаге было равно 174, вторично инфицировались 25 человек, общее число общавшихся в очагах - 915 человек. Таким образом показатель первичной очаговой заболеваемости был равен $190,15 \pm 12,97 \%$ $\left(x^{2}=307,43 ; \quad p<0,001\right)$, общей очаговой заболеваемости - $217,49 \pm 13,64 \%$ o $\quad x^{2}=41,49$; $\mathrm{p}<0,001)$, что статистически значимо выше по сравнению со средне-краевым показателем,

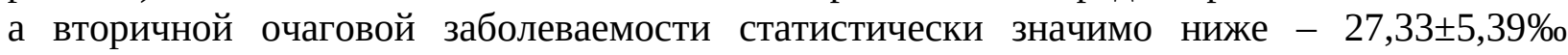
$\left(x^{2}=15,02, p<0,001\right)$ (рис. 3).

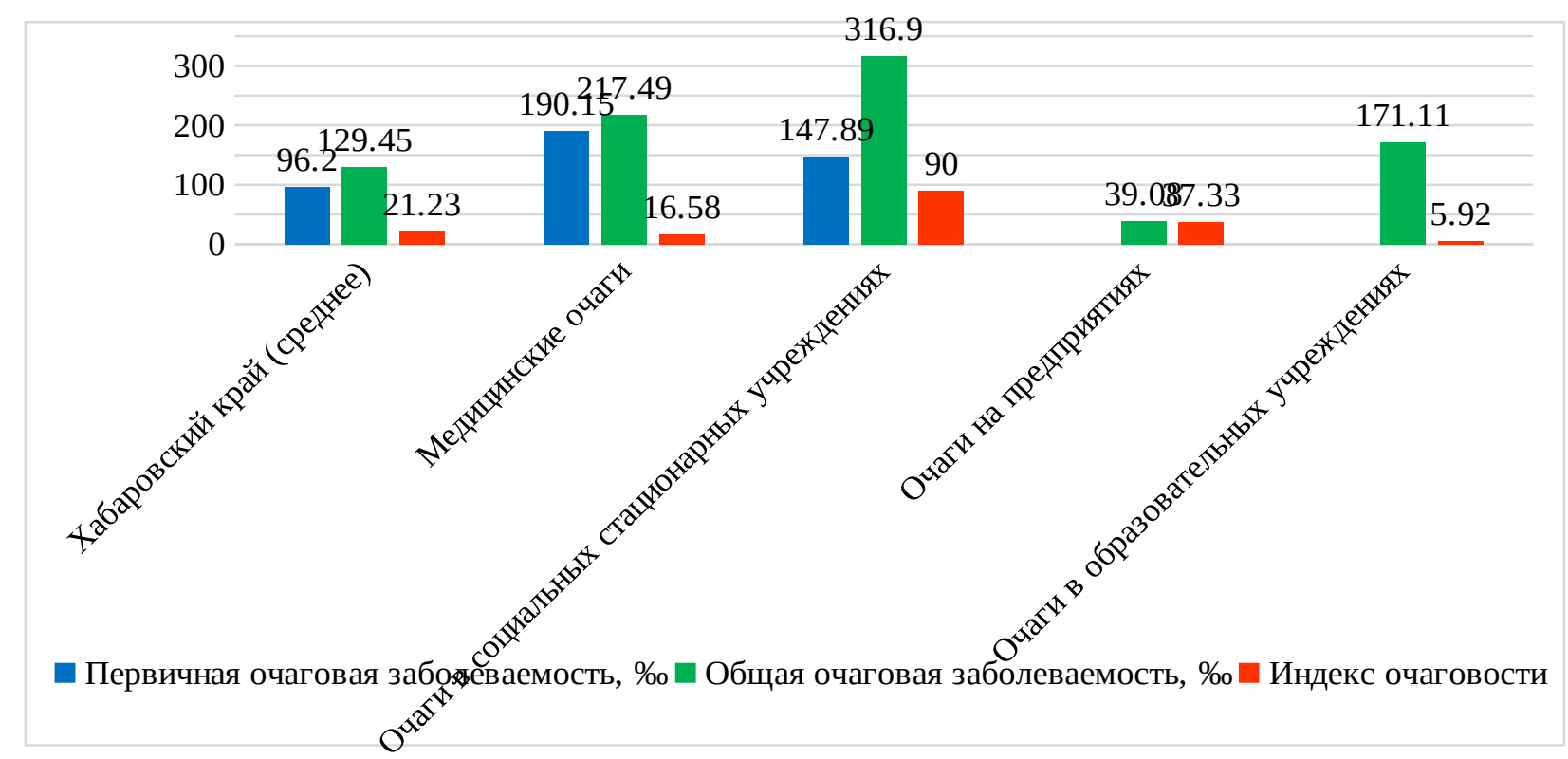

Рис. 3. Интенсивность эпидемического процесса в зависимости от типа очага

Летальность в медицинских очагах была равна $1,00 \pm 0,70 \%$, доля внебольничных пневмоний $-14,07 \pm 2,46 \%$, ОРВИ - 10,55 $\pm 2,18 \%$, бессимптомного течения COVID-19 75,38 $\pm 3,05 \%$ (рис. 4).

Средняя длительность активности очагов групповой заболеваемости COVID-19 в

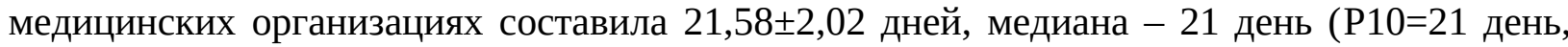
$\mathrm{P} 90=21$ день), наименьшая длительность активности очага - 21 день, наибольшая - 28 дней. 
В очагах, зарегистрированных в социальных стационарных учреждениях, ИО был равен 90 человек, что оказалось наивысшим показателем среди всех проанализированных типов очагов Хабаровского края. Количество первично инфицированных в очагах данного типа равнялось 126, вторично инфицировались 144 человека, суммарное количество общавшихся в очагах данной группы - 852 человека. Уровень первичной заболеваемости в очагах составил $147,89 \pm 12,16 \%$ о $\left(x^{2}=37,8 ; \mathrm{p}<0,001\right)$, вторичной заболеваемости -

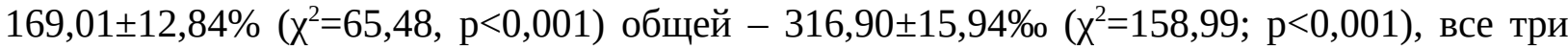
значения оказались статистически значимо выше аналогичных средних показателей по Хабаровскому краю. Летальность в данной группе очагов составила $1,48 \pm 0,73 \%$, доля

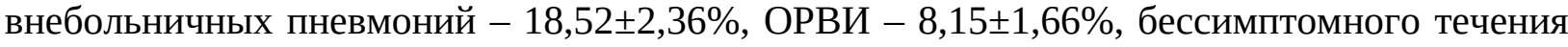


течения, закончившихся летальным исходом, у подопечных указанных учреждений, что наиболее вероятно связано с пожилым возрастом подопечных социальных учреждений, наличием у них сопутствующих хронических заболеваний и тесными контактами внутри учреждений. Так, по данным литературы, новая коронавирусная инфекция у больных старше 60 лет с хроническими болезнями часто протекает в тяжелой форме, летальность при которой может достигать 3-5\% [8], и напротив, для лиц в возрасте до 50 лет и без сопутствующей патологии характерна высокая частота случаев COVID-19 более легкого и бессимптомного течения [13].

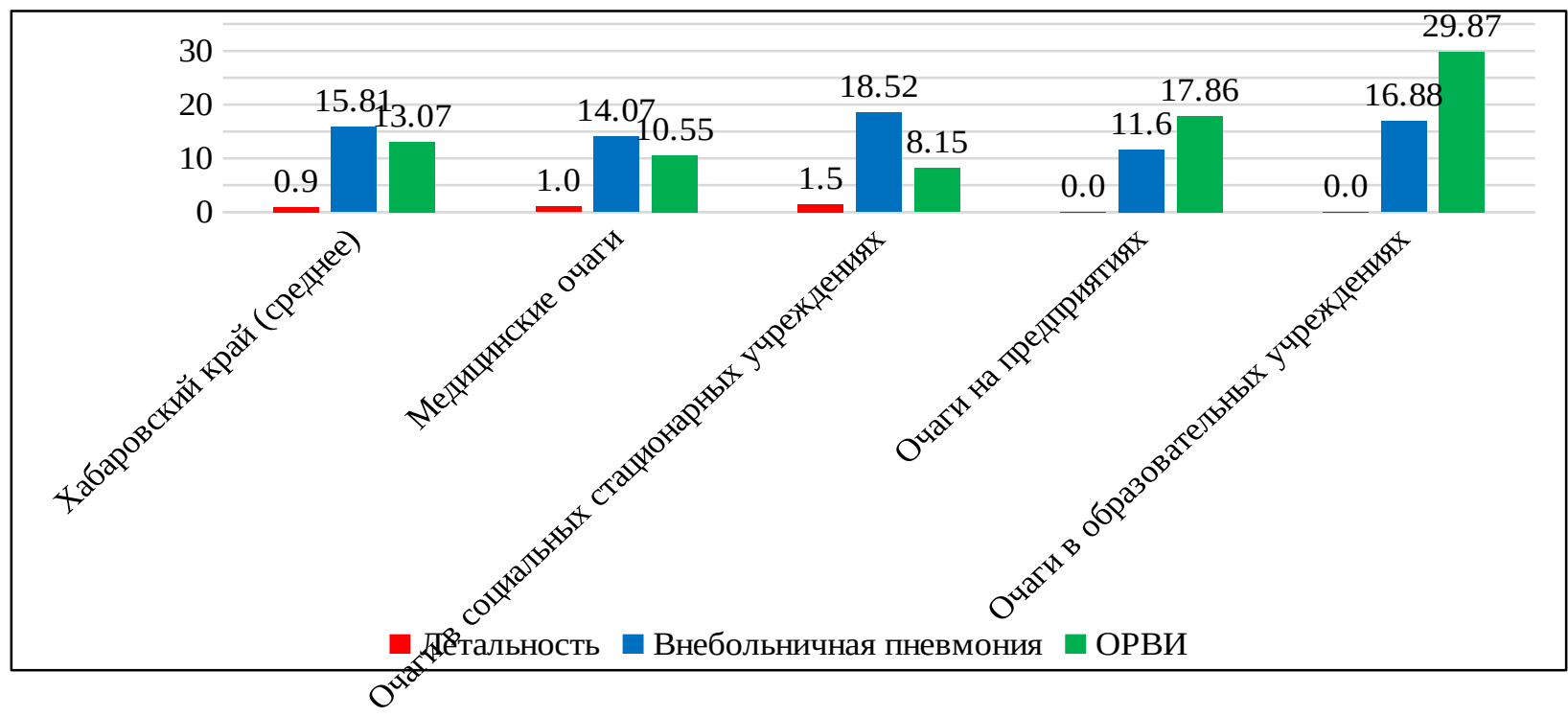

\section{Рис. 4. Сравнительная характеристика показателей летальности и удельного веса нозологических форм COVID-19 (\%) в очагах с множественными случаями заболеваний.}

В настоящем исследовании в социальных стационарных организациях удельный вес относительно легкого течения COVID-19 (в форме ОРВИ) оказался статистически значимо ниже средне-краевого значения $\left(\mathrm{x}^{2}=4,51 ; \mathrm{p}=0,034\right)$. Все три очага групповой заболеваемости, зафиксированные в социальных стационарных учреждениях Хабаровского края, имели максимальную длительность активности, равную 28 дням.

Среди промышленных предприятий, в числе которых оказались нефтеперерабатывающий завод и организации, использующие вахтовый метод работы, суммарное количество инфицированных в 3 очагах было равно 112, вторично 
инфицированных лиц не зарегистрировано, а среднее количество заразившихся COVID-19 в эпидемическом очаге (ИО) составило 37,33. Суммарное число общавшихся в очагах данной группы - 2866 человек. Показатель общей очаговой заболеваемости в коллективах промышленных предприятий оказался наименьшим из всех проанализированных типов очагов и равнялся $39,08 \pm 3,62 \%$, что $\left(x^{2}=177,54, p<0,001\right)$. Удельный вес внебольничных пневмоний составил $11,61 \pm 3,03 \%$, ОРВИ - 17,86 $\pm 3,62 \%$, бессимптомных форм инфекции


заболеваемости, зафиксированные на предприятиях, имели длительность активности, равную 21 дню.

В группе очагов, сформированных в образовательных организациях, количество заразившихся COVID-19 составило 77 человек, ИО оказался наименьшим и был равен 5,92. Суммарное количество общавшихся в очагах данного типа составило 450 человек, вторично инфицированных лиц не зарегистрировано, однако показатель общей (в данном случае первичной) очаговой заболеваемости оказался достаточно высоким $171,11 \pm 17,75 \%$, и статистически значимо превысил среднее значение в Хабаровском крае $\left(x^{2}=7,75 ; p=0,006\right)$. Удельный вес внебольничной пневмонии составил $16,88 \pm 4,27 \%$. Отличительной особенностью эпидемических очагов групповой заболеваемости, зарегистрированных в образовательных организациях Хабаровского края, является наиболее частая регистрация легкого течения COVID-19 - в форме ОРВИ. Их удельный

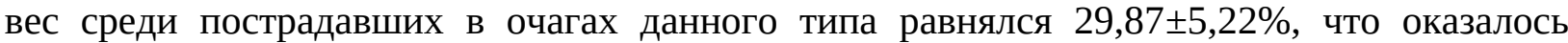
статистически значимо выше аналогичного среднего значения по краю $\left(x^{2}=13,29\right.$; p $<0,001)$. Бессимптомные формы инфекции в эпидемических очагах, сформированных в учреждениях системы образования, составили 53,25 $\pm 5,69 \%$ и были статистически значимо ниже, чем в очагах других типов, и меньше средне-краевого показателя $(71,12 \pm 1,77 \%$, $\left.x^{2}=10,35 ; p=0,002\right)$. Летальных исходов в очагах групповой заболеваемости COVID-19, регистрируемой в образовательных организациях, не отмечено.

В 13 очагах групповой заболеваемости COVID-19, сформировавшихся в образовательных учреждениях, средняя длительность активности очага составила 22,61 $\pm 3,07$ дней, медиана - 21 день (P10=21 день, P90=28 дней), наименьшая длительность активности очага - 21 день, наибольшая - 28 дней.

\section{Обсуждение результатов исследования}

При обобщении полученных результатов исследования установлено, что самая высокая степень активности ЭП при COVID-19 наблюдается при формировании очагов групповой заболеваемости в социальных стационарных учреждениях, которая проявилась наибольшим (средним на 1 очаг) числом заболевших/инфицированных COVID-19, самыми высокими показателями общей и вторичной заболеваемости инфекцией (при расчете на 1000 общавшихся в очаге) и наибольшей длительностью активности ЭП в очагах. В эпидемических очагах данного типа внебольничные пневмонии в структуре клинических проявлений COVID-19 встречались чаще, чем в других учреждениях, кроме того, зарегистрированы случаи летальных исходов заболевания. К факторам, влияющим на большую степень восприимчивости к инфекции подопечных социальных стационарных учреждений, относятся пожилой возраст, обуславливающий снижение активности иммунной системы и сопротивляемости организма $\mathrm{K}$ патогенным возбудителям, наличие иммунодефицитных состояний и фоновых заболеваний у пациентов, многочисленность ослабленного контингента, возникновение нераспознанных источников инфекции, увеличение числа контактов с ними в условиях коллективной переуплотнённости, тесного и постоянного общения, способствующего более быстрой передаче возбудителей инфекции воздушно-капельным и контактно-бытовым путями [14, 15].

В Хабаровском крае несколько меньшая, но также высокая по степени интенсивности активность ЭП COVID-19 отмечена в очагах групповой заболеваемости, 
сформированных в медицинских организациях. Критериями высокой активности ЭП в очагах данного типа можно считать достаточно большой уровень общей заболеваемости COVID-19, приходящийся в среднем на 1 эпидемический очаг, регистрацию вторичной заболеваемости среди контактных с первично заболевшими лицами и наличие летальных исходов среди заболевших в очагах. Вклад медицинских работников в общую групповую заболеваемость COVID-19, зарегистрированную в лечебно-профилактических учреждениях края, оказался на достаточно высоком уровне: из общего числа

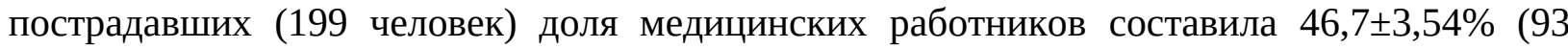
человека). Таким образом, в настоящем наблюдении показано существование реального риска заноса COVID-19 в медицинские организации как пациентами, так и медицинским персоналом.

Следует особо отметить регистрацию тяжелых форм инфекции, закончившихся летальным исходом, только в двух типах эпидемических очагов COVID-19 Хабаровского края - в социальных стационарных учреждениях и медицинских организациях, что требует особого внимания со стороны медицинской общественности и социальных служб. Известно, что тяжелое течение заболевания в очагах инфекции с распространением в коллективах способствует не только возникновению неблагоприятных исходов, но и большей степени эпидемической опасности больного для окружающих лиц $[7,10]$.

Меньшая степень активности ЭП COVID-19 отмечена в очагах групповой заболеваемости, зарегистрированных на крупных промышленных предприятиях и в образовательных организациях. Для очагов указанных типов оказались не характерными летальные исходы заболеваний и вторичные случаи заболеваний среди контактных с первично заболевшими лицами. Вполне вероятно, что данный факт обусловлен своевременными мерами изоляции заболевших и возможностями более полного разобщения контактных лиц между собой и с источниками инфекций. Однако круг контактных лиц был значительно шире на промышленных предприятиях, чем суммарно во всех организациях, вовлеченных в данный анализ (соответственно, удельный вес контактных среди общавшихся в очагах промышленных предприятий составил $96,09 \pm 0,36 \%$ против аналогичного среднего значения по краю $-87,5 \pm 0,47 \%, \mathrm{p}<0,001)$.

Отличительными особенностями очагов групповой заболеваемости в образовательных организациях стали достаточно существенный уровень первичной заболеваемости COVID-19 (171,11 $17,75 \%$ ), статистически значимо наиболее высокий



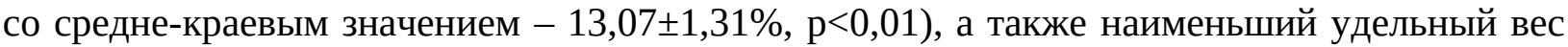
бессимптомных форм инфекции $(53,25 \pm 5,69 \%$ против среднего по краю $-71,12 \pm 1,77 \%$, $\mathrm{p}<0,01)$.

Критерий средней продолжительности (длительности) вспышек может являться отражением правильности постановки диагноза, своевременности и эффективности проведения необходимых противоэпидемических мероприятий. За исключением социальных стационарных учреждений, средняя длительность существования очагов в остальных организациях Хабаровского края была практически одинаковой (от 21 дня на промышленных предприятиях до 22,61 дня в образовательных учреждениях).

Достоверность выводов об оценке эпидемической значимости различных типов очагов групповой заболеваемости COVID-19 получена методом суммы ранговых значений выше перечисленных показателей активности эпидемического процесса с учетом доверительных границ [11]. Продемонстрированный в таблице 2 статистический анализ эпидемической значимости активности ЭП в различных типах очагов групповой заболеваемости COVID-19 подтвердил, что наиболее неблагоприятная ситуация складывается в социальных стационарных учреждениях. Учитывая особый контингент, проживающий в данных учреждениях, а именно пожилой возраст, наличие множества сопутствующих заболеваний, а также частые и тесные контакты межу сотрудниками и подопечными, сделанный вывод является вполне закономерным. Второе место по 
активности эпидемического процесса при COVID-19 занимают медицинские организации, а наименьшая активность ЭП характерна для вспышек на рабочих предприятиях и в образовательных учреждениях. 
Характеристика очагов COVID-19 с распространением в организованных коллективах Хабаровского края

Таблица 2. по критериям активности эпидемического процесса

\begin{tabular}{|c|c|c|c|c|c|c|c|c|c|c|c|c|c|}
\hline \multirow{2}{*}{$\begin{array}{c}\text { Тип } \\
\text { эпидемического } \\
\text { очага с } \\
\text { распространение } \\
\text { м в } \\
\text { организованных } \\
\text { коллективах }\end{array}$} & \multicolumn{2}{|c|}{$\begin{array}{c}\text { Индекс } \\
\text { очаговости } \\
\text { (ИО) }\end{array}$} & \multicolumn{2}{|c|}{$\begin{array}{c}\text { Общая } \\
\text { заболеваемость } \\
\text { на } 1000 \text { общав- } \\
\text { шихся в очаге }\end{array}$} & \multicolumn{2}{|c|}{$\begin{array}{c}\text { Вторичная } \\
\text { заболеваемость } \\
\text { среди контакт- } \\
\text { ных в очаге }\end{array}$} & \multicolumn{2}{|c|}{$\begin{array}{c}\text { Средняя } \\
\text { длительность } \\
\text { существования } \\
\text { очага }\end{array}$} & \multicolumn{2}{|c|}{$\begin{array}{c}\text { Средний } \\
\text { удельный вес } \\
\text { ВП в очагах }\end{array}$} & \multicolumn{2}{|c|}{$\begin{array}{c}\text { Средний } \\
\text { уровень } \\
\text { летальности в } \\
\text { очагах }\end{array}$} & \multirow[t]{2}{*}{$\begin{array}{l}\text { Сумма } \\
\text { рангов }\end{array}$} \\
\hline & $\begin{array}{c}\text { Коли- } \\
\text { чество } \\
\text { человек }\end{array}$ & $\begin{array}{l}\text { Ранго- } \\
\text { вое } \\
\text { значе- } \\
\text { ние }\end{array}$ & $\%$ & $\begin{array}{l}\text { Ранго- } \\
\text { вое } \\
\text { значе- } \\
\text { ние }\end{array}$ & $\%$ & $\begin{array}{l}\text { Ранго- } \\
\text { вое } \\
\text { значе- } \\
\text { ние }\end{array}$ & $\begin{array}{l}\text { Коли- } \\
\text { чество } \\
\text { дней }\end{array}$ & $\begin{array}{l}\text { Ранго- } \\
\text { вое } \\
\text { значе- } \\
\text { ние }\end{array}$ & $\%$ & $\begin{array}{l}\text { Ранго- } \\
\text { вое } \\
\text { значе- } \\
\text { ние }\end{array}$ & $\%$ & $\begin{array}{l}\text { Ранго- } \\
\text { вое } \\
\text { значе- } \\
\text { ние }\end{array}$ & \\
\hline $\begin{array}{c}\text { Социальные } \\
\text { стационарные } \\
\text { учреждения }\end{array}$ & 90,00 & 1 & $\begin{array}{l}316,90 \\
\pm 15,94\end{array}$ & 1 & $\begin{array}{l}169,01 \\
\pm 12,84\end{array}$ & 1 & 28,00 & 1 & $\begin{array}{l}18,52 \\
\pm 2,36\end{array}$ & 1 & $\begin{array}{c}1,48 \\
\pm 0,73\end{array}$ & $2,5^{*}$ & 7,5 \\
\hline $\begin{array}{l}\text { Медицинские } \\
\text { организации }\end{array}$ & 16,58 & 3 & $\begin{array}{l}217,49 \\
\pm 13,64\end{array}$ & 2 & $\begin{array}{l}27,33 \\
\pm 5,39\end{array}$ & 2 & 21,58 & 3* & $\begin{array}{l}14,07 \\
\pm 2,46\end{array}$ & $3,5 *$ & $\begin{array}{c}1,00 \\
\pm 0,47\end{array}$ & $2,5^{*}$ & 16 \\
\hline Предприятия & 37,33 & 2 & $\begin{array}{l}39,08 \\
\pm 3,62\end{array}$ & 4 & 0 & $3,5^{*}$ & 21,00 & 3* & $\begin{array}{l}11,61 \\
\pm 3,03\end{array}$ & $3,5^{*}$ & 0 & $2,5^{*}$ & 18,5 \\
\hline $\begin{array}{c}\text { Образовательные } \\
\text { учреждения }\end{array}$ & 5,92 & 4 & $\begin{array}{l}171,11 \\
\pm 17,75\end{array}$ & 3 & 0 & $3,5^{*}$ & 22,61 & $3 *$ & $\begin{array}{l}16,88 \\
\pm 4,27\end{array}$ & 2 & 0 & $2,5^{*}$ & 18 \\
\hline Сумма рангов & - & 10 & - & 10 & - & 10 & - & 10 & - & 10 & - & 10 & 60 \\
\hline
\end{tabular}

Примечание: * - статистически значимых отличий между показателями с одинаковыми ранговыми номерами установить не удалось 


\section{Заключение}

Таким образом, в настоящей работе применён эпидемиологический подход, позволяющий выявить закономерности распределения групповой заболеваемости новой коронавирусной инфекцией в организованных коллективах. Различия в распространении COVID-19, выявленные в разных типах очагов групповой заболеваемости, дают основание выделить критерии высокой активности ЭП, к которым, по нашему мнению, следует отнести: индекс очаговости, превышающий 21 чел.; показатель первичной заболеваемости, составляющий более 96\% среди всех общавшихся в эпидемическом очаге; регистрация вторичных заболеваний в очагах, то есть из числа контактных лиц; наличие в очаге достаточно высокой доли наиболее тяжелых форм проявления инфекции в виде внебольничной пневмонии; регистрация летальных исходов заболевания среди заболевших в эпидемических очагах; длительность функционирования эпидемического очага новой коронавирусной инфекции более 21 дня.

Возникновение вспышечной заболеваемости в организованных коллективах может косвенно свидетельствовать о качестве и эффективности профилактических и противоэпидемических мероприятий. На основе предложенных критериев активности ЭП может быть использован дифференцированный подход к проведению мер профилактики в очагах групповой заболеваемости COVID-19 с различной степенью активности и течения эпидемического процесса. В коллективах с высоким риском распространения COVID-19, в которых вероятность возникновения вспышечной заболеваемости особенно велика, наиболее оправдан усиленный комплекс постоянно действующих мер, упреждающих занос и распространение новой коронавирусной инфекции.

\section{Источники литературы:}

1. Инфекционные болезни и эпидемиология: Учебник / В.И. Покровский, Г.С. Пак, Н.И. Брико, Б.К. Данилкин. 2-ое изд. М.: ГЭОТАР-Медиа, 2007. 816 с.: ил.

2. Patel MC, Chaisson LH, Borgetti S, et al. Asymptomatic SARS-CoV-2 infection and COVID-19 mortality during an outbreak investigation in a skilled nursing facility. Clin Infect Dis. 2020;ciaa763. doi:10.1093/cid/ciaa763.

3. Arons MM, Hatfield KM, Reddy SC, et al. Presymptomatic SARS-CoV-2 infections and transmission in a skilled nursing facility. N Engl J Med. DOI: 10.1056/NEJMoa2008457.

4. Roxby AC, Greninger AL, Hatfield KM, et al. Outbreak Investigation of COVID-19 Among Residents and Staff of an Independent and Assisted Living Community for Older Adults in Seattle, Washington. JAMA Intern Med. 2020;180(8):1101-1105. doi:10.1001/jamainternmed.2020.2233.

5. Семёнов А.В., Пшеничная Н.Ю. Рождённая в Ухане: уроки эпидемии COVID-19 в Китае. Инфекция и иммунитет. 2020;10(2):210-220. Doi: 10.15789/2220-7619-BIW-1453.

6. Jin Y-H., Cai L., Cheng Z-S. et al. A rapid advice guideline for the diagnosis and treatment of 2019 novel coronavirus (2019-nCoV) infected pneumonia (standard version) // Mil Med Res. - 2020. - №7 (1): 4. DOI: 10.1186/s40779-020-0233-6.

7. Воронина Н.В., Гороховский В.С., Дьяченко С.В., Жмеренецкий К.В., Кольцов И.П., Куцый М.Б., Сазонова Е.Н., Сенькевич О.А., Томилка Г.С. COVID-19: только научные факты. Дальневосточный медицинский журнал. 2020;1:5-22. DOI: 10.35177/19945191-2020-1-5-22.

8. Брико Н.И., Каграманян И.Н., Никифоров В.В., Суранова Т.Г., Чернявская О.П., Полежаева H.A. Пандемия COVID-19. Меры борьбы с её распространением в Российской Федерации. Эпидемиология и Вакцинопрофилактика. 2020;19(2):4-12. DOI: 10.31631/2073-3046-2020-19-2-4-12.

9. Plan L.T., Nguyen T.V., Luong Q.C. et al. Importation and human-to-human transmission of a novel coronavirus in Vietnam // N Engl J Med. - 2020. - №382 (9). - P. 872874. DOI: 10.1056/NEJMc2001272. 
10. Wu D., Wu T., Liu Q., Yang Z. The SARS-CoV-2 outbreak: what we know // Int J Infect Dis; 2020. DOI: 10.1016/j.ijid.2020.03.004 [Epub ahead of print].

11. Общая эпидемиология с основами доказательной медицины: руководство к практическим занятиям: учеб. Пособие / под ред. В.И. Покровского, Н.И. Брико. - 2-ое изд., испр. и доп. М.: ГЭОТАР-Медиа, 2012. 496 с.: ил. ISBN 978-5-9704-1778-2.

12. Шкарин В.В., Саперкин Н.В., Благонравова А.С. Вспышечная заболеваемость в России (по данным государственных докладов «О санитарно-эпидемиологической обстановке в Российской Федерации»). Эпидемиология и инфекционные болезни. Актуальные вопросы; 2013.5:4-9.

13. Кутырев В.В., Попова А.Ю., Смоленский В.Ю., Ежлова Е.Б., Демина Ю.В., Сафронов В.А., Карнаухов И.Г., Иванова А.В., Щербакова С.А. Эпидемиологические особенности новой коронавирусной инфекции (COVID-19). Сообщение 2: особенности течение эпидемического процесса COVID-19 во взаимосвязи с проводимыми противоэпидемическими мероприятиями в мире и Российской Федерации. Проблемы особо опасных инфекций. 2020;2:6-12. DOI: 10.21055/0370-1069-2020-2-6-12.

14. Boccia S., Ricciardi W., Ioannidis J.P. What other countries can learn from Italy during the COVID-19 pandemic. JAMA Int. Med; 2020.180(7):927-928. Doi: 10.1001/jamainternmed.2020.1447.

15. Семенов А.В., Пшеничная Н.Ю. Уроки эпидемии COVID-19 в Италии. Инфекция и иммунитет; 2020.10(3):410-420. Doi: 10.15789/2220-7619-LTL-1468.

\section{Сведения об авторах:}

Троценко Ольга Евгеньевна - Д.м.н., директор, ФБУН Хабаровский НИИ эпидемиологии и микробиологии Роспотребнадзора, 680610, г. Хабаровск, ул. Шевченко 2, тел.: (4212) 325228; e-mail: trotsenko_oe@hniiem.ru

Зайцева Татьяна Анатольевна - руководитель, Управление Федеральной службы по надзору в сфере защиты прав потребителей и благополучия человека по Хабаровскому краю; 680009, г. Хабаровск, ул. Карла Маркса, 109 б., тел.: (4212) 274744, e-mail: root@sanepid.khv.ru

Базыкина Елена Анатольевна - научный сотрудник, ФБУН Хабаровский НИИ эпидемиологии и микробиологии Роспотребнадзора, 680610, г. Хабаровск, ул. Шевченко 2, тел.: (4212) 325228; e-mail: adm@hniiem.ru

Корита Татьяна Васильевна - к.м.Н., ученый секретарь, ФБУН Хабаровский НИИ эпидемиологии и микробиологии Роспотребнадзора, 680610, г. Хабаровск, ул. Шевченко 2, тел.: (4212) 325228; e-mail: adm@hniiem.ru

Гарбуз Юрий Алексеевич - главный врач, ФБУЗ "Центр Гигиены и Эпидемиологии в Хабаровском Крае", 680021, Хабаровский край, город Хабаровск, Владивостокская улица, (4212) 32-47-13; e-mail: fbuz@27.khv.ru

Каравянская Татьяна Николаевна - начальник эпидемиологического отдела, Управление Федеральной службы по надзору в сфере защиты прав потребителей и благополучия человека по Хабаровскому краю; 680009, г. Хабаровск, ул. Карла Маркса, 109 б., тел.: (4212) 274744, e-mail: root@sanepid.khv.ru

Присяжнюк Елена Николаевна - заместитель главного врача по эпидемиологическим вопросам, ФБУЗ "Центр Гигиены и Эпидемиологии в Хабаровском Крае"680021, Хабаровский край, город Хабаровск, Владивостокская улица, (4212) 32-47-13; e-mail: fbuz@27.khv.ru 